\section{Now Gosport: what next?}

The editorial on the dreadful events at Gosport held my interest for a variety of reasons, as I'm sure it did my colleagues.'

The mention of Harold Shipman however led me up another path. Although Shipman was an odious man whose deplorable behaviour ultimately led to a predictable ending, I cannot let the opportunity pass to comment on the expression 'commit suicide'.

In all aspects of health care, language is important. We no longer use words like cretin, spastic, loony, or Mongol. Suicide was once a crime - and, in religious circles, a sin - hence the phrase 'commit suicide'. Better to use phrases such as died by suicide' or 'took/ended their life', and not to use expressions such as 'failed/successful attempt' or 'committed/completed suicide'.

Stigmatising language fosters shame and discourages people from opening up to talk - thus reducing opportunities to intervene and offer help.

The phrase also causes further distress to those left behind - adding to the pain, shame, and guilt that most people bereaved by suicide experience. Samaritans have a helpful page on their website, ${ }^{2}$ and Today broadcast a short interview on the topic on 10 September. ${ }^{3}$

Susan Beaton, an Australian suicide prevention adviser, has written an excellent review article that eloquently discusses the reasons for why language counts in describing this most socially unacceptable way of dying. ${ }^{4}$ It is freely available on the web.

Alison E Payne,

GP, Willenhall Primary Care Centre,

Coventry.

Email: alison.payne3lanhs.net

\section{REFERENCES}

1. Pocock L, Forbes K, Reid C, Purdy S. Now Gosport: what next? Br J Gen Pract 2018; DOI: https://doi.org/10.3399/bjgp18X698393

2. Samaritans. Suicide reporting - additional points to consider. 2018. https://www.samaritans.org/ media-centre/media-guidelines-reporting-suicide/ best-practice-suicide-reporting-tips/suicide laccessed 6 Nov 2018).
3. Gordon B. How to talk about suicide. Today 2018 10 Sep: https://www.bbc.co.uk/programmes/ p06ks22n (accessed 6 Nov 2018).

4. Beaton S, Forster P, Maple M. Suicide and language: why we shouldn't use the ' $\mathrm{C}$ ' word. InPsych, the Bulletin of the Australian Psychological Society 2014; Feb: 30-31.

DOI: https://doi.org/10.3399/bjgp18X699917

\section{A change is needed, a change is coming}

I try not to feel angry, but a few weeks ago in A\&E I was sitting with my 6-month-old daughter quite angry. She had awoken early in the morning upset with a temperature and discharge from her ear. I had been unable to get an appointment with either my GP or a MIAMI clinic. What should have been a 10-minute GP slot was instead a 3-hour wait in $A \& E$.

Fast forward a few days and I woke up in an uncomfortable sweat, not unusual for our heatwave but with the added discomfort of a throbbing painful ear. As the pain increased I realised I may need antibiotics. At this point I would (again) have thought of the race to get a GP appointment except I was on holiday in Catalonia, Spain.

A quick change of the day's plan and I was being seen at a local health centre with my daughter in tow, for me this time. handed over my European health insurance card (EHIC) and was triaged, seen by the doctor, and given a prescription within an hour and a half. I used my limited Spanish to get directions to the pharmacy, receiving a week's course of amoxicillin and 60 paracetamol for around €5 (€4.50).

I thought about my trip when I got home. 'The contrast in the time difference to see a doctor in the two units was significant, likely reflecting their workload. How much would I have paid for the medication at home? At least double the price. Is it even possible in the UK to prescribe 60 paracetamol? But most importantly what care if any would my EHIC entitle me to next year? I'm thinking perhaps we'll have a staycation, I've heard Center Parcs is great for kids.
Imogen Green,

Paediatric ST2, Royal Alex Children's

Hospital, Brighton.

Email: imogen.greenlanhs.net

DOI: https://doi.org/10.3399/bjgp18X699929

\section{Overenthusiastic prescribing of vitamin D, the sunlight vitamin}

Today's prescribers want to act scientifically and with kindness but perhaps they need to heed lessons from the past. ${ }^{1}$

Many of the patient problems that are commonly presented today feature low mood and fatigue, with aches and pains. Enter the sunlight vitamin as the cause of such problems. Blood measurements of vitamin $D$ confirm low levels in nearly one-third of the population. Despite the fact that there is no scientific evidence that giving vitamin $D$ supplements helps these conditions, prescribing is given on the chance that it might help, and justified by the laboratory tests.

This reminded me of the famous quack doctor in the time of Pepys called Lionel Lockyer whose miracle pills contained sunbeams. Regarded as a universal medicine in its day, the tablets sold so well that he amassed a small fortune and had a large semi-recumbent figure of himself with an epitaph placed on his tomb in Southwark Cathedral, London.

Perhaps the prescribing of vitamin $D$ medication is becoming the modernday equivalent of this historical medical misadventure.

Nigel Masters,

Retired GP, Highfield Surgery, High Wycombe.

Email: mastersnigellagmail.com

\section{REFERENCE}

1. Jones R. Medication, medication. Br J Gen Pract 2018; DOI: https://doi.org/10.3399/bjgp18X698909.

DOI: https://doi.org/10.3399/bjgp18X699941 